\title{
Sexual violence and free speech in popular music
}

\author{
Rosemary Lucy Hill \& Heather Savigny
}

Popular Music $38(2)$

(forthcoming, accepted August 2018)

\section{Abstract}

This article re-examines the use of arguments in favour of free speech when faced with difficult subjects in music, such as sexual violence against women. We present a new perspective on the 1985 US Senate Hearing on Record Labeling and challenge the orthodoxy that the Hearing was only a matter of free speech. Using critical discourse analysis we argue that the sexist environment of the Hearing, the misogyny of the musicians, plus homosocial bonding resulted in the PMRC's arguments being unaddressed as attention turned to censorship. Subsequent academic work has continued to focus on censorship, neglecting to investigate how music can propagate dangerous representations. This article indicates the need for a shift in popular music studies towards careful consideration of those aspects which are difficult and dangerous for women. It therefore opens up popular music to important new areas for critical examination and feminist analysis.

\section{Keywords}

Censorship, freedom of speech, heavy metal, PMRC, popular music, sexual violence.

\section{Introduction}

As the creator of 'Under the Blade,' I can say categorically that the only sadomasochism, bondage, and rape in this song is in the mind of Ms. Gore. (Snider in 
US Senate, 1985, pp.74-75)

Twisted Sister's Dee Snider responded to criticism of the band's song 'Under The Blade' in his statement to the Senate Hearing on Record Labeling in 1985, by suggesting that Tipper Gore, a member of the pro-record labelling group the Parents Music Resource Center (PMRC), had a prurient turn of mind. The Hearing has come to be seen as part of a symbolic victory for the rights of musicians to free artistic expression in the face of overly intrusive criticism from conservative mothers. It is also, for us, emblematic of the sexism directed at rock music's critics which has served to direct attention away from serious allegations of, amongst other things, sexual violence and redirect it towards arguments about censorship, thus negating the key concerns and thwarting any attempt to discuss the musical representation of violence against women.

Today, sexual violence in the media is again coming under fire from feminists, raising important questions about what it means to come into contact with misogynistic violence through culture. In this article we present a new perspective on the 1985 US Senate Hearing on Record Labeling and ask, how has 'censorship' become the dominant discourse rather than the harms of cultural violence, and with what effect? Using discourse analysis of the Hearing, we argue that it opened up a high level political space to talk about the depiction of women and sexual violence in music, but that the gendered form of the Senate Hearing, the sexist statements of the responding musicians (including Snider, alongside Frank Zappa and John Denver) and homosocial bonding between musicians and senators played a key role in undermining the female critics and muting their argument.

We begin by examining the academic debate about the Hearing and its impact before 
turning our attention to the arguments about sexual violence made at the Hearing, and the strategies employed by the opposing witnesses to reframe the discussion. We address the gendered nature of free speech before considering the harms of violent depictions of women made by men in the media and finally returning to what the implications are for popular music studies. The Hearing was a significant moment in which to address cultural representations of misogyny and in particular representations of violence against women, but, we argue, it was an opportunity missed.

\section{The PMRC and sexual violence}

The Record Labeling Senate Hearing was brought about by the campaigning of the PMRC, an organisation of wealthy and politically connected women, including Tipper Gore, wife of Senator Al Gore, and Susan Baker, whose husband was Treasury Secretary James Baker. They were arguing for more information about the lyrical contents of records.

Simultaneously, this was an era when widespread public debates about sexual violence and pornography had reached new heights in the UK, US and globally (Dines, 2010). The Hearing can be seen as part of a broader conservative backlash against the perceived permissiveness of the 1960s and 1970s, and as part of a revival of interest in family morals. This was in the context of feminist progress in the legal and political arena following the work of Dworkin, Mackinnon and a plethora of feminist activists, writers and academics, resulting in what Susan Faludi terms a 'backlash' (1991). Furthermore, the Hearing took place as Reagan's neoliberal policies were gaining ground, emphasising industry self-regulation rather than legislation. It is also highly relevant that MTV gave pop music newly heightened visibility, 
bringing music video directly into American homes.

By 1985 the PMRC had developed a high profile media presence using shocking examples of what they regarded as dangerous music. This included a list of songs called the 'Filthy Fifteen'i, which they viewed as some of the worst examples of pop songs. The criteria for the list were violence, drugs and alcohol, sex/masturbation and the occult. Artists included in the list were Prince, Madonna, AC/DC, Twisted Sister and other heavy metal bands. The PMRC sought for the record industry to voluntarily apply stickers and a rating system (as in the film industry) to records so that parents would know what they were buying for their children. It is important to note that the members of the PMRC did not call themselves feminists, preferring to self-identify as mothers.

At the Hearing, the PMRC argue that the lyrical and visual imagery of popular music, heavy metal in particular, are damaging for children who are too young to understand what they are seeing and Hearing. To elucidate their argument about sexual violence the campaigners spotlight the US heavy metal band W.A.S.P., showing the cover of their single 'Animal (Fuck Like A Beast)' (1984), which depicts a bloodied circular saw emerging from a tiger print cod piece, connoting that the wearer had just eviscerated someone with the penis-substitute blade, and citing the song lyrics.

Susan Baker states the following:

The material we are concerned about cannot be compared with Louie Louie, Cole Porter, Billie Holliday, et cetera. Cole Porter's 'the birds do it, the bees do it,' can hardly be compared with WASP, 'I f-u-c-k like a beast.' There is a new element of 
vulgarity and violence toward women that is unprecedented.

While a few outrageous recordings have always existed in the past, the proliferation of songs glorifying rape, sadomasochism, incest, the occult, and suicide by a growing number of bands illustrates this escalating trend that is alarming.

Some say there is no cause for concern. We believe there is. Teen pregnancies and teenage suicide rates are at epidemic proportions today. The Noedecker Report states that in the United States of America we have the highest teen pregnancy rate of any developed country: 96 out of 1,000 teenage girls become pregnant.

Rape is up 7 percent in the latest statistics, and the suicide rates of youth between 16 and 24 has gone up 300 percent in the last three decades while the adult level has remained the same. (Baker in US Senate, 1985, p.12)

Baker makes a comparison between the euphemistic music of the past to W.A.S.P.'s much more explicit song title (and to the Judas Priest song 'Eat Me Alive'), describing it as 'vulgar' and noting it for the violence towards women. Their argument rests on the assertion of the innocence and development of children, and on their own need, as mothers, to protect children from knowing too much, too soonii. More broadly, the music is presented as worrying because the mainstream presence of such songs (on MTV, in part) correlates with a rise in teen pregnancy and rape, amongst other things. In reviewing Tipper Gore's book (1987), Philip Gordon calls this logic the 'monkey see/monkey do philosophy of communication' (1989, p.120), i.e. it is flawed logic to assert that we are directly influenced 
by the media to behave in particular ways. Nevertheless, the PMRC identify that violence against women is being used for entertainment and their stance provides the kernel of an important critique of cultural representations of women. That they did not call themselves feminists, bring in feminist witnesses (e.g. Dworkin and MacKinnon) or allude to feminist arguments is part of their ethical appeal: in not using feminist arguments the PMRC separate themselves from the dangerous associations of being radical, instead portraying themselves as average, moderate American mothers. The PMRC present a thoroughly evidenced case, using statistics, expert witnesses and lyrical examples. However, the three musicians do not address this evidence or the PMRC's claims at all.

In fact sexual violence falls out of the discussion altogether in favour of a discourse of censorship and freedom of speech underpinned by (and underpinning of) American patriotism. Indeed the responses of Frank Zappa, John Denver and a letter from the American Civil Liberties Union's which was read out, are all about freedom of speech and address none of the concerns about sexual explicitness, drugs, Satanism or violence. For Zappa in particular, the Hearing is about freedom of artistic expression: he views a rating system on records as stigmatising for artists and impediment to their freedom of speech. He begins by quoting the First Amendment, thereby setting the tone for what follows as a defence of the American constitution and what it means to be an American. For John Denver, 'access to all perspectives of an issue' is important, and if those perspectives are unpleasant they 'sooner or later become boring' (Denver in US Senate, 1985, p.66): censorship is therefore not only unnecessary. Both Zappa and Denver refer in their testimony to Nazi Germany, arguing that rating records is the first step to censorship and a 'slippery slope' into totalitarianism. Yet the PMRC state that censorship is not what they 
want. We understand Zappa and Denver as using a reductio ad Hitlerum (Strauss, 1953)

technique: the members of the PMRC are compared to Hitler, even though their argument is being misrepresented. The reductio ad Hitlerum argument thereby distracts from the PMRC's main concerns of the potential damage to children from cultural violence and sex. It is also a form of personal attack, to which we return below. Debates around free speech came to dominate not only the Hearing itself, but also the music media responses (particularly within heavy metal) and the academic discussion in media and cultural studies.

\section{The discourse of censorship and the PMRC}

Indicative of the dominant focus on censorship in academic studies is Claude Chastagner (1999) who, in reviewing the impact of the PMRC argues that for all the group's claims to be anti-censorship, the trial ushered in a new era of antagonism towards popular music in which censorship did happen. The trials against Jello Biafra and 2 Live Crew are cases in point. Lawrence Grossberg (2014) makes a similar argument: that the role of the PMRC was to 'police the boundaries of rock' $(2014$, p.5), put power in the hands of parents, and 'to some extent, the patriarchal government' $(2014$, p.5). He views this as part of a broader 'attack on rock' that had become insidious in US culture. Christopher Schneider (2011) posits that in relation to rap, the moral panic served to present a framing of censorship as the dominant discourse in relation to the genre, thus directing the spotlight to some musical examples and not others (e.g. those that did not fit into the sexist and violent examples). Moreover Chastagner (1999) is convinced that the campaigning of the PMRC was a distraction from more serious issues in which working class white men and later, when the attention was turned to rap, the black community were scapegoated. 
In dismissing the PMRC's arguments, Chastagner is following Frank Zappa's lead. There is a history of male academics taking on uncritically the arguments of their research subjects (McRobbie and Garber, 1978; Thornton, 1995), and we posit that this is part of what has happened in the case of the Senate Hearing and the PMRC. The persuasive arguments of the charismatic and, in music circles, extremely well-respected Frank Zappa have been taken on by the mostly male academics writing about the case. The result is that the sexual violence named by the PMRC not only falls out of the discussion at the Hearing, but it also falls out of the academic discussion too. Furthermore, the focus on free speech presents it in a binary relationship with censorship, the one necessarily good, the other necessarily bad. This leaves little room for nuanced discussion of what censorship may be for or what the impacts of some forms of speech may be. Certainly, in the case of the Senate Hearing, it obliterates any space to ask questions of what it means for sexual violence to be part of the imagery of popular music.

One of the only social science studies to seek for a more subtle understanding of the arguments of the PMRC is metal scholar Deena Weinstein (2000 [1991]). In writing the first book length study of heavy metal Weinstein directly addresses the PMRC's criticisms and seeks to defend the genre. Notably, however, whilst she pays close attention to the judgements that the genre promotes extreme violence, sexual perversion, drugs and Satanism (as does Natalie Purcell, 2003), the charge of sexual violence does not come under her microscope. Indeed, she argues, like Chastagner, that the PMRC 's assertion that they were not promoting censorship 'must be understood as a rhetorical smokescreen' (2000 [1991], p.265); she, like the musicians in the Hearing that we discuss below, therefore does not take the accusations of sexual violence seriously. Keith Kahn-Harris, in discussing the 
slightly later panic (and his own disquiet) around Cannibal Corpse's 'Fucked With A Knife', argues against censorship in favour of 'intellectual inquiry' (2003, p.94).

The moral panic around the content of popular music also prompted a number of psychological studies into the effects of heavy metal and rap on young listeners. These studies typically used methods such as testing people's attitudes before and after listening to different types of popular music. Alan Rubin, Daniel West and Wendy Mitchell's (2001) review of the literature found that metal and rock makes listeners more sexist, but Tasha Howe and Howard Friedman (2014) in their review found that the studies were inconclusive as to the effects of listening on attitudes and behaviour. There is a good deal to be critical about in these kinds of 'media effects' studies (Gauntlett, 2006), including that they do not pay attention to the heterogeneity of the heavy metal genre (Lind, 2017), and they are unclear as to whether it is the music or the lyrics having effects. Typically psychology studies into the negative effects of music on the listener have been roundly dismissed by popular music scholars, with the effect that discussions of the potentially harmful content of music have fallen by the wayside. Bruce Johnson and Martin Cloonan's (2009) examination of music and violence is a lonely exception, but they too can only conclude that the evidence is ambiguous about whether music can cause people to be violent. Moreover, we posit that direct effects of engaging with media (e.g. watching rape and then raping someone) are not the only kinds of impacts that cultural representations have; thinking about how representations and discourses work in more subtle ways is important, a point to which we will return.

The academic discourse about the Hearing and about the PMRC campaign is therefore 
dominated by the problem of censorship and by the need to wrest music from the grasp of those who would seek to 'police' it. Whilst we do not agree with all of the PMRC's claims (e.g. they disapprove of lyrical portrayals of female sexual arousal which we would argue are a key aspect of the feminist aim to 'write the body' and to reclaim female sexuality) and our fundamental ideological positions are quite different, we are clear that in raising the question of misogynistic representations of sexual violence they had a good point. The dismissal of their claim and the allied triumphalism of the representations of the Hearing as a victory for rock music and free speech are deeply worrying. We now examine how the debate was reframed as an issue of free speech and argue that the musicians' personal attacks of members of the PMRC, homosocial bonding between musicians and senators and the gendered environment of the Hearing itself are vital to the reframing.

\section{Sexist personal attack}

Frank Zappa's main technique as a witness is to discredit the members of the PMRC because they are women, because they are mothers. He describes the proposal of the PMRC as 'an ill-conceived piece of nonsense' (Zappa in US Senate, 1985, p.53). In doing so he draws on discourses which questions the capacity of women to present 'rational' arguments. Moreover, he questions their credibility by suggesting that the PMRC of buy Prince and Sheena Easton records to appear sophisticated, rather than because they are genuinely interested in the music, thus suggesting that this is not music for them, for mothers, mobilising the sexist assumption that mothers are no good judges of music (Frith, 2007). This is also a classed criticism, as he criticises them for feelings of over-privileged entitlement. He further characterises the PMRC as meddling hobbyists who are overstepping their role as 
wives and mothers, implying that they should get back into the nursery and stop distracting the men from the important business of government:

Whilst the wife of the Secretary of the Treasury recites 'Gonna drive my love inside you' and Senator Gore's wife talks about 'bondage' and 'oral sex at gunpoint' on the CBS Evening News, people in high places work on a tax bill that is so ridiculous, the only way to sneak it through is to keep the public's mind on something else: Porn rock. (Zappa in US Senate, 1985, p.54)

This suggests that the women are using the lewd lyrics for the own ends - to distract the public from the Home Audio Recording Tax - and this is evidence for Zappa that they are not serious about their aims; indeed there is the implication that the women are only raising the issue of the lyrics at the behest of the men in their lives. Furthermore, like Dee Snider in the quote with which we began this article, he hints that the women are salaciously enjoying the lyrics they cite.

The argumentum ad hominem (or perhaps ad feminem ${ }^{i i}$ ) attack on the members of the PMRC distracts from the issue of sexual violence by undermining their authority to speak, and it does so on the same grounds as those on which they claim authority to speak: as mothers. What is deeply concerning is that the personal attacks then enable Zappa to use the term 'celebrate sexuality' in the context of songwriters being denied their right to artistic expression, even though the references he has previously made to 'oral sex at gunpoint' are references to rape: the sexual violence now drops out of the argument because sexual violence is situated as nothing more than a celebration of male sexuality which relies on a heteronormative reading of men's entitlement to women's bodies (c.f. Pateman, 1988). 


\section{Homosocial bonding in the service of hegemonic masculinity}

The second strategy that displaces the discussion of sexual violence (and all the other aspects identified as problematic by the PMRC) is the male bonding that occurs between the senators and two of the musicians: Frank Zappa and John Denver. The ratio of men to women at the Hearing is 2:1, but although the PMRC employed men as expert witnesses, the members themselves are all women and their argument rests on the assertion that they are mothers (the ethical appeal). The musicians were all men. ${ }^{\text {iv }}$ The result of this imbalance, of the PMRC's mobilisation of motherhood and Zappa's sexist attack, is that the debate about record labelling ends up looking like a struggle against maternal authority. Back to Aristotle we see women excluded from their rights to have voice in public life and public spaces. While women have subsequently established their rights to speak in public life, it is notable that the role of the mother is presented as of particularly lesser value in the public realm, as evidenced by Zappa's testimony. Critical mass matters and as the majority of the senators at the Hearing were male and it is to them that the musicians address their statements. In doing so a rapport develops between musicians and senators based on their similar identification with the male role and their dis-identification with the devalued mother role. A rejection of mothers and femininity is a fundamental trope of rock music (Kearney, 2017) and this plays an essential part in bringing together the senators and the musicians, who already share a privileged position through their sex and race.

Senator Al Gore makes a point of announcing his fandom of both Zappa and John Denver, describing Zappa as a 'true original and a tremendously talented musician' (Gore in US Senate, 1985, p.56). In doing so he aligns himself with the musicians and their 
(countercultural) values, rather than his wife's (more conservative) arguments. Furthermore, Zappa tries to create common feeling with Gore as well, claiming to know his mind: 'I do not want to have that [Government or 'somebody's wife' telling my children what to think] and I do not think you do either' (Zappa in US Senate, 1985, p.57). The Chairman (Senator John C. Danforth) thanks John Denver for his 'excellent statement' (Danforth in US Senate, 1985, p.68); Senator Ernest F. Hollings declares himself 'delighted to work with [Denver] on this' (Hollings in US Senate, 1985, p.69) and goes on to draw a commonality along the lines of not being television watchers: 'you and I are the same' (1985, p.70). Denver himself is very respectful of the senators, apologising for interrupting. The effect of all this verbal backslapping is to create a sense of common feeling amongst the men. They present themselves as on the same page and sharing the same values, just needing to iron out the details. The personal attacks towards members of the PMRC made by Zappa, and to a lesser degree by Snider, deepen the alliance of the men in the room (see Kehily and Nayak, 1997 for further discussion of how men use sexist humour for bonding). We view this male-bonding as the actions involved in developing hegemonic relationships between men (Connell, 1995). In doing so, the women, who are addressed by Zappa as 'the ladies' and by the Chairman as 'the mothers', are debarred, diminished and undermined.

\section{Free speech as a gendered concept and the gendered context of the Senate Hearing}

The result of these strategies is to shift the discussion away from sexual violence (as well as drugs, suicide and Satanism) and to place the entire emphasis on the issue of civil liberties, artistic freedom and free speech. We argue that this displacement is a problem because it prevented discussion of what was dangerous in the depiction of women as objects upon which sexual violence could be enacted; but also because the free speech reframing is based 
on a masculinist and misogynistic discourse that means women's rights will necessarily play second fiddle to liberal ideals' first violin. To be successful, we contend that a free speech argument is needed which treats speech as relational, i.e. rather than just being about the right of the speaker to air their views, the rights of the listener must be taken into account. There is no definition of what constitutes free speech in the First Amendment; during the Senate Hearing 'freedom of speech' appears to have been interpreted by the musicians as speech with untrammelled limits, and as an essential component of liberty. In On Liberty (2007 [1859]), J. S. Mill writes that the only sufficient principle for interventions and the restriction of liberty is the Harm principle: 'The only purpose for which power can be rightfully exercised over any member of a civilized community, against his will, is to prevent harm to others' (Mill, 2007 [1859], p.68). However, as has been discussed within the academic literature, Mill does not fully come to a conclusion as to what constitutes 'harm', and this is at the crux of the issue in relation to the defence of free speech. That 'harm' becomes open to definition, as we will argue below, means that hegemonic masculinity (Connell, 1995) becomes replicated in and through these discourses rather than challenged. Justification for free speech is often rooted in liberal ideological assumptions emphasising individual autonomy; the success of framing the discussion of free speech in these individual terms however, renders invisible the structural basis of power which provides the context within which such discussions take place. We challenge the roots of these individualising assumptions and argue that it is not possible to understand the ways in which power works, without an understanding of the context. As other critical scholars have argued, to ignore the context is to ignore the ways in which power works. In focusing 
attention on individuals we ignore the underlying 'fraternal patriarchy' as the basis for political rights. The trick, as Carole Pateman observes, has been to 'insist that "fraternity" is universal and nothing more than a metaphor for community' (Pateman, 1988, p.114). That is, a universal community of men and their interests. And so, to understand the workings of the Senate Hearing, we have to extend beyond conceiving of these as solely about the actions of individual senators, musicians and members of the PMRC. Rather the Hearing took place in a wider political context. That context is one that is also gendered; as Lawless and Fox argue, 'the organs of government were designed by men, are operated by men, and continue to be controlled by men' $(2005$, p.10). Here then we see a system designed by men, and enacted in the interests of men; the rules of the game are thus designed to advantage those who created that game.

This institutional design of course, is situated in an ideological context whereby the parameters of what counts as political speech takes place in the 'public sphere' (2013, p.21). As Fraser observes, this space has historically been not only male dominated but solely concerned with the interests of the white male bourgeoisie. The interests of a diversity of women are thus marginalised since their voices are structured out of discussions within that public sphere (Fraser, 2013). Zappa's sexist attack directed at members of the PMRC is indicative of the kind of environment into which the PMRC took their campaign. When women's voices are critiqued not on the basis of their argument, but on the basis of their being women this begins from a position where women are 'othered' as different from, and a threat to, men and masculinised structures of power. In the Senate Hearing, discursive strategies focused attention on women's gender, rather than the argument being made. Moreover, this environment of fraternal patriarchy subsequently 
protects the rights of men to speak as they please about women (and it is noticeable perhaps that while hate speech includes race and sexuality, hate speech against women is still not illegal). In this way, we see systems structured in misogyny interrupt free speech: a male dominated Senate Hearing taking place within masculinised structures which were clearly hostile to women. In this sense, we contend that the Senate Hearing took place in a densely structured social and cultural context that, we argue, was structured by 'hegemonic masculinity' (Connell, 1995) and a masculinised public sphere (Fraser, (2013). Thus we argue that the playing field was set: the moment the PMRC walked into the Hearing to make their case, they arrived in a context that was already structurally biased against them.

The result is that the discursive repositioning of the PMRC's concerns around male sexual violence against women as a free speech issue was underpinned by structural gender bias. This structural bias thus served to provide the basis of an effective ideational and ideological context wherein masculine interests systemically predominated. Gendered structures self-replicate if their gendered nature is not called into account. As Nancy Fraser (2013) observes, gender blindness does not equate to a lack of gender inequality. Rather, conceptual discussions which ignore gender serve to reinforce the status quo. The reproduction of power structures thus contain 'the assumption of sameness [which] seems to have an inbuilt tendency to be insensitive to the needs of women' (Stevenson, 1995, p.72). Thereby within debates around free speech, women's concerns are bracketed off rather than free speech functioning as a mechanism through which social inequalities and injustices can be eliminated. In the case of the Senate Hearing, the civil liberties argument ignored this relational nature of free speech, and so served to structurally embed violence against women, rather than prevent it. 


\section{The harms of cultural representations of sexual violence against women}

Unlike the PMRC and the psychology 'media effects' studies, we are not arguing that there are direct causal links between cultural depictions of male sexual violence towards women and the actual acts. That the media have direct effects remains contested territory; nevertheless the cultural representations around us do still do work in the world. Our concern is with the discursive production, circulation and legitimation of male sexual violence against women and the cultural context in which such behaviour begins to appear acceptable. Representations matter. They have power in the world because they not only provide a particular depiction of the world, but because in themselves they make up the world (Hall, 1997). They are not only culture in the sense of art, but they are culture in the sense that they are part of our everyday existence. In this sense, then, we argue that to only discuss violent representations as an issue of free speech is to fundamentally argue for a world in which women are devalued, marginalised and violated. Indeed it is not only the visual and lyrical representations of women in songs to whom this is happening, but to members of the PMRC during the Hearing. Such an argument necessarily raises important questions about what counts as violence, whose perspective on what counts matters, and how do we account for different readings of cultural violence? Furthermore, what does it mean for society itself when representations of violence are used as a leisure pursuit?

The Senate Hearing provided a space for reflection on these issues, and the ways in which popular culture forms part of our wider social and cultural discourses. Depictions of sexual violence against women in popular culture matter: there is no shortage of work that explores the problems associated with these types of representations as part of a wider landscape that has been described as 'rape culture' (Buchwald, Fletcher and Roth, 1993; 
Mendes, Keller and Ringrose, 2018). This term describes the cultural normalisation of sexual violence where some cultural contexts rely on male violence against women. For Sarah Projansky (2001) this includes the military and war, but we could also extend this to video games such as Grand Theft Auto; popular music (for example Eminem, Robin Thicke); sexual violence in advertising (Stankiewicz and Rosselli, 2008); US presidential campaigns (Anderson, 2011); sexual violence as part of the 'pornification' of popular culture in mainstream media (Gill, 2011; Levy, 2006; Douglas, 2010) and online (Banyard, 2011). This work shows that media and cultural depictions of male violence against women are harmful. They form part of a wider cultural context which includes actual violence against women (Carter and Weaver, 2003; Michelle and Weaver, 2003). This cultural phenomenon is then underpinned by conceptions of the 'male gaze' (Mulvey, 1975); women as objects to be looked at rather than active agents. This matters as it legitimates and normalises this kind of imagery and representation; and as we know from authors such as Andrea Dworkin (1981) the commonplace use of this kind of imagery and representation of rape and sexual violence serves to harm women. ${ }^{v}$

Within this wider cultural context, rock music's problematic representations of women have been a focus of feminist analysis since at least the 1970s (e.g. Rat, 2013 [1970]; Coates, 1997; Whiteley, 2000; Kearney, 2017). More recently work specifically on heavy metal takes aim at bands like Cannibal Corpse for the overt sexual violence in their lyrics (Kahn-Harris, 2003; Vasan, 2011; Barron, 2013), or in the imagery and artwork (Overell, 2014). This excellent work is a strong start to understanding what kind of sexual violence is apparent in heavy metal. ${ }^{\text {vi }}$ Further psychology studies highlight that sexualised images of women are not without problems for viewers. They show that: such images induce objectified appraisals of 
women by men (Daniels and Wartena, 2011); women internalise media representations of what a 'perfect' body should look like (Halliwell, Malson and Tischner, 2011); there may be a correlation between viewing pornography/sexual violence and engaging in sexual harassment and violence (Bonino, Ciairano, Rabaglietti and Cattelino, 2006); and that the more visible sexual violence against women is in media outlets, the more likely it is to become normalised, and seen as acceptable (Malamuth and Briere, 1986; Malamuth and Check, 1985; Malamuth and Check, 1981; Linz, Donnerstein and Penrod, 1988) (and which in turn can also become a legitimated part of the homosocial bonding process).

We are not seeking here to make a strong argument about media effects and we acknowledge the dispute over the notion that media could have such direct 'effects' on audiences. To accept that media have direct effects would be to assume a passivity on the part of audiences, as if we are empty vessels to be filled with media messages and ideological content. The flipside of this debate is that audiences are 'active' in the information we seek and retain, and have the capacity to identify meaning in media texts and autonomously choose to accept or reject media messages (for a summary see Gauntlett, 2006). Indeed, these latter assumptions are made by protagonists of 'free speech' in the Senate Hearing, notably it is a key part of John Denver's statement. However, to accept that audiences are entirely active in all that they consume is to remove accountability from media and culture producers as to what is published and produced. In this sense then, if audiences are entirely autonomous and independent, logically there would be no need for any form of media regulation. But we do have forms of media regulation (for example age recommendations on films) which thus suggests a recognition that media are not neutral or ineffective, rather they do have the capacity to influence the cultural context within which 
audiences receive and evaluate information (and entertainment). Jenny Kitzinger brings these two aforementioned dichotomous positions together in her work on media coverage and sexual abuse. In it she argues that in spite and sometimes even because of [...] audience engagement, $[\ldots]$ media can have a very powerful role in defining, maintaining, and even transforming the way we see the world' $(2004$, p.31). We thus argue that the ways in which male sexual violence against women is depicted in popular culture matters. Not because audiences are easily malleable passive dupes, but rather because the assumption of agency in relation to media messages actually serves to structurally embed and normalise these messages, thereby legitimating this form of violence.

\section{Popular music studies and sexual violence}

Johnson and Cloonan (2009) argue that, as a field of study, popular music studies (PMS) has been too focused on the positive aspect of music, particularly with regards to its facilitation of community and identity formation. The negative side of music is rarely considered because popular music scholars tend to be fans and therefore on the defensive. ${ }^{\text {vii }}$ Furthermore, because PMS has a marginalised place in the academy, researchers have felt the necessity of asserting the status of the field. Whilst we can certainly attest to the truth of defensive nature of popular music scholarship in relation to metal music studies (e.g. Weinstein, 2000 [1991]; Purcell, 2003), we contend that this is not the whole story. Johnson and Cloonan (2009) go on to argue that the long held assumption among PMS scholars (after, but not including Adorno) that music is beneficial has led to, amongst other things, 'an unswerving critique of any form of censorship' (Frith 2004 cited in Johnson and Cloonan, 2009, p.9) - and the authors are unaware of any PMS work that does call for censorship or even that highlights the negative effects of music. We argue that the focus on censorship is 
part of the problem in itself, not just an effect of other factors (e.g. defensiveness). As we have shown, the construction of censorship as a problem for liberal societies has produced a discourse in which popular music is taken to be a key marker of 'free speech' and therefore to be defended at all costs. The lack of discussion of music's darker side is therefore the effect of the dominance of the censorship discourse, rather than the other way round.

How, then, can scholars shift the discussion of such music past or away from the overpowering discourse of censorship to consider the problem of sexual violence in music? We might start with the artists making such music. Why do they seek to make violent misogynistic music? What is their purpose in doing so? Who is it for? What work in the world do they want the song to do? What are their duties and obligations to the world? How do we view the music of male artists who have violated women? (c.f. McKittrick and Weheliye, 2017). We do not suggest that artists should not be culpable or excepted from questioning based on the grounds of 'artistic freedom'. Indeed, the opposite. We argue that if artists choose to make misogynistic music which depicts male sexual violence against women then feminists should equally be able to choose to question their gender politics. To divert those questions or to attack those asking can be regarded as a form of censorship in itself.

We might also ask questions of those who choose to listen to the music. What do they like about the music and lyrics? What do they dislike? Do they recognise it as misogynistic? How does the song fit in with their existing politics? How do they feel the song? Why do they listen to the music if they understand it to be misogynistic? Again, how does role play fit in? The answers to such questions might tell us something about the roles of art and subcultural allegiance in making political statements. They might enable us to theorise further about the 
meaning making practices involved in musical participation (including listening). We argue that listeners should actively engage with the ideas that their favoured music tells them, that listeners have a duty to think carefully about to whom they are giving their money (even if it is only peanuts, such as streaming revenue). Our own discomfort as fans of bands with questionable morals is part of this active engagement.

Reflecting on these questions also speaks to a wider research agenda, one that we do not have space to cover within this article, but nonetheless raises important issues that remind us of the significance of the relationship between music and society. What does the existence of such songs tell us about society? What does it mean when people buy records featuring, and others make a profit off, sexual violence? What theoretical frameworks might be useful to help us understand the phenomenon of sexual violence in music? Such an approach might also be extended to consider some of the other aspects of the 'dark side of the tune' (Johnson and Cloonan, 2009) such as fascism and homophobia in song lyrics and artwork, and in artists' utterances in interviews and other arenas. These questions and concerns clearly form part of the bigger difficulty which troubles us (and others) as feminists: how is it possible to enjoy art and culture that represents a divergence from our own politics, that may even offend us or cause us harm? There is, therefore, work to be done that goes beyond the 1985 moment to encompass important questions about our engagement with culture, both as producers and consumers.

\section{Conclusion}

The 1985 Senate Hearing on Record Labeling was a key moment in addressing musical portrayals of sexual violence against women. Sexism underpinned the reframing of the 
discussion as a contest over freedom of speech, rather than about violence against women. We have argued that this reframing was an opportunity lost: male sexual violence remains today a common trope in media and cultural discourse, and also in popular music. The Senate Hearing represented a 'critical moment' whereby this issue could be tackled, but was not. It also represents a systematic reasserting of patriarchal interests in the face of increasing women's rights. In mapping the discourse of cultural production around this issue, we have demonstrated how this reframing as an issue of 'censorship' represents a 'moment lost' in opportunities to challenge the cultural normalisation of male sexual violence against women, and this goes for academic work as much as for senators and musicians. In the neoliberal context, the result is that the market is allowed to determine the ways in which women, men, sex and sexual violence are depicted, and thus such tropes remain valued selling points for corporations: misogyny is treated as leisure, violence against women becomes recreation. Furthermore, the masculinist arena of the Senate Hearing itself means that musical sexual violence now has all the appearance of being sanctioned by the US state, a situation which is further endorsed by the election of a 'pussy grabbing' president.

Fundamentally, this article presents a new perspective on the Record Labeling Senate Hearing and challenges the orthodoxy that the Hearing was only a matter of free speech and defending rock ' $n$ ' roll. In revisiting the Hearing we have shown how the free speech/censorship argument was used in the service of sexism, thus shutting down any further discussion about the potential harms of popular music, particularly when it comes to sexual violence against women. This article therefore marks a shift in the direction of studies on popular music away from consideration of the positive aspects of the music towards careful interrogation of those aspects which are difficult and dangerous for women. It 
therefore opens up popular music to important new areas for critical examination.

\section{Bibliography}

Anderson, K.V. 2011. '"Rhymes with blunt": pornification and U.S. political culture'. Rhetoric and Public Affairs. 14/2, pp. 327-368.

Banyard, K. 2011. The equality illusion: the truth about women and men today (Faber, London).

Barron, L. 2013. 'Dworkin's nightmare: porngrind as the sound of feminist fears ', in: Heavy metal: controversies and countercultures, Hjelm, T., et al. eds. (Equinox, Sheffield), pp. 66-82.

Bonino, S., S. Ciairano, E. Rabaglietti and E. Cattelino. 2006. 'Use of pornography and self-reported engagement in sexual violence among adolescents'. European Journal of Developmental Psychology. 3/3, pp. 265-288.

Buchwald, E., P.R. Fletcher and M. Roth eds. 1993. Transforming a rape culture (Milkweed Editions, Minneapolis).

Carter, C. and C.K. Weaver. 2003. Violence and the media (Open University Press, Buckingham).

Chastagner, C. 1999. 'The parents' music resource center: From information to censorship'. Popular Music. 18/2, pp. 179.

Coates, N. 1997. '(R)evolution now? Rock and the political potential of gender', in: Sexing the groove: popular music and gender, Whiteley, S. ed. (Routledge, Abingdon), pp. 50-64.

Connell, R.W. 1995. Masculinities (Polity, Cambridge).

Daniels, E.A. and H. Wartena. 2011. 'Athlete or sex symbol: what boys think of media representations of female athletes'. Sex Roles. 65/7, pp. 566-579.

Dines, G. 2010. Pornland: how porn has hijacked our sexuality (Beacon Press, Boston, MA).

Douglas, S.J. 2010. The rise of enlightened sexism: how pop culture took us from girl power to girls gone wild (St Martin's Griffin, New York). 
Dworkin, A. 1981. Pornography: men possessing women (The Women's Press, London).

Fraser, N. 2013. Fortunes of feminism (Verso, London).

Frith, S. 2007. 'The unpopular and the unpleasant: thoughts inspired by the work of James Blunt', in: New Directions In Popular Culture conference, 21 March, Leeds.

Gauntlett, D. 2006. 'Ten things wrong with the media 'effects' model', in: Critical readings: violence and the media, Weaver, C.K. and Carter, C. eds. (Open University Press, Maidenhead), pp. 5466.

Gill, R. 2011. 'Sexism reloaded, or, it's time to get angry again!'. Feminist Media Studies. 11/01, pp. 61-71.

Gordon, P. 1989. 'Raising PG Kids in an X-Rated Society. By Tipper Gore. Nashville: Parthenon Press, 1987. 219 pp. De Snider's Teenage Survival Guide or How to Be a Legend in Your Own Lunchtime. By Dee Snider and Philip Bashe. Garden City, N.Y.: Doubleday, 1987. 240 pp'. Popular Music. 8/1, pp. 120-122.

Gore, T. 1987. Raising PG kids in an X-rated society (Parthenon Press, Nashville).

Grossberg, L. 2014. We gottta get out of this place: popular conservatism and postmodern culture (Routledge, London).

Hall, S. ed. 1997. Representation: cultural representations and signifying practices (The Open University, Milton Keynes).

Halliwell, E., H. Malson and I. Tischner. 2011. 'Are contemporary media images which seem to display women as sexually empowered actually harmful to women?'. Psychology of Women Quarterly. 35/1, pp. 38-45.

Horeck, T. 2014. '\#AskThicke: "Blurred Lines," rape culture, and the feminist hashtag takeover'. Feminist Media Studies. 14/6, pp. 1105-1107.

Howe, T.R. and H.S. Friedman. 2014. 'Sex and gender in the 1980s heavy metal scene: groupies, musicians, and fans recall their experiences'. Sexuality \& Culture. 18/3, pp. 608-629. 
Johnson, B. and M. Cloonan. 2009. Dark side of the tune: popular music and violence (Ashgate, Farnham).

Kahn-Harris, K. 2003. 'Death metal and the limits of musical expression', in: Policing pop, Cloonan, M. and Garofalo, R. eds. (Temple University Press, Philadelphia), pp. 81-99.

Kearney, M.C. 2017. Gender and rock (Oxford University Press, New York).

Kehily, M.J. and A. Nayak. 1997. '"Lads and laughter": humour and the production of heterosexual hierarchies'. Gender and Education. 9/1, pp. 69-88.

Kitzinger, J. 2004. Framing abuse: media influence and public understanding of sexual violence against children (Pluto, London).

Lawless, J.L. and R.L. Fox. 2005. It takes a candidate: why women don't run for office (Cambridge University Press, New York).

Levy, A. 2006. Female chauvinist pigs: women and the rise of raunch culture New ed (Pocket Books, London).

Lind, T.T. 2017. 'Defending agression, demented and otherwise, in metal music'. Metal Music Studies. forthcoming, $\mathrm{pp}$.

Linz, D.G., E. Donnerstein and S. Penrod. 1988. 'Effects of long-term exposure to violent and sexually degrading depictions of women'. Journal of Personality and Social Psychology. 55/Nov 88, pp. 758-768.

Malamuth, N.M. and J. Briere. 1986. 'Sexual violence in the media: indirect effects on aggression against women'. Journal of Social Issues. 42/1986, pp. 75-92.

Malamuth, N.M. and J.V.P. Check. 1981. 'The effects of mass media exposure on acceptance of violence against women: A field experiment'. Journal of Research in Personality. 15/4, pp. 436-446.

Malamuth, N.M. and J.V.P. Check. 1985. 'The effects of aggressive pornography on beliefs in rape myths: individual differences'. Journal of Research in Personality. 19/3, pp. 299-320. 
McKittrick, K. and A.G. Weheliye. 2017. '808s \& heartbreak'. Propter Nos. 2/1, pp. 13-42.

McRobbie, A. and J. Garber. 1978. 'Girls and subcultures', in: Resistance through rituals, Hall, S. and Jefferson, T. eds. (Hutchinson London, pp. 209-222.

Mendes, K., J.M. Keller and J. Ringrose. 2018. Digital feminist activism: women and girls fight back against rape culture (Oxford University Press, Oxford).

Michelle, C. and C.K. Weaver. 2003. 'Discursive manoeuvres and hegemonic recuperations in New Zealand documentary representations of domestic violence'. Feminist Media Studies. 3/3, pp. 283-299.

Mill, J.S. 2007 [1859]. On liberty (Penguin, London).

Mulvey, L. 1975. 'Visual pleasure and narrative cinema'. Screen. 16/3, pp. 6-18.

Overell, R. 2014. Affective intensities in extreme music scenes: cases from Australia and Japan (Palgrave Macmillan, Basingstoke).

Pateman, C. 1988. The sexual contract (Polity, Cambridge).

Projansky, S. 2001. Watching rape: film and television in postfeminist culture (New York University Press, New York).

Purcell, N.J. 2003. Death metal music: the passion and politics of a subculture (McFarland, London).

Rafalovich, A. and A. Scneider. 2005. 'Song lyrics in contemporary metal music as counter-hegemonic discourse: an exploration of three themes'. Free inquiry in creative sociology. 33/2, pp. 131142.

Rat. 2013 [1970]. 'Cock rock: men always seem to end up on top', in: The rock history reader, Cateforis, T. ed. Second ed. (Routledge, Abingdon), pp. 119-124.

Rubin, A.M., D.V. West and W.S. Mitchell. 2001. 'Differences in aggression, attitudes toward women, and distrust as reflected in popular music preferences'. Media Psychology. 3/1, pp. 25-42.

Schneider, C.J. 2011. 'Culture, rap music, "bitch," and the development of the censorship frame'. American Behavioral Scientist. 55/1, pp. 36-56. 
Stankiewicz, J.M. and F. Rosselli. 2008. 'Women as sex objects and victims in print advertisements'. Sex Roles. 58, pp. 579-589.

Stevenson, N. 1995. 'Habermas, mass culture and the public sphere', in: Understanding media cultures: social theories and mass communication, Stevenson, N. ed. (Sage, London), pp. 4774.

Strauss, L. 1953. Natural right and history (University of Chicago Press, London).

Thornton, S. 1995. Club cultures: music, media and subcultural capital (Polity, Cambridge).

US Senate. 1985. Committee on Commerce, Science and Transportation: Contents of music and the lyrics of records (U.S. Government Printing Office, Washington).

Vasan, S. 2011. 'The price of rebellion: gender boundaries in the death metal scene'. Journal for Cultural Research. 15/3, pp. 333-349.

Weinstein, D. 2000 [1991]. Heavy metal: the music and its culture Rev. ed (Da Capo Press, Boulder, Colo.).

Whiteley, S. 2000. Women and popular music: sexuality, identity, and subjectivity (Routledge, New York).

\begin{tabular}{llll}
\hline i The 'Filthy Fifteen' were: & & \\
1 & Prince & Darling Nikki & sex, masturbation \\
2 & Sheena Easton & Sugar Walls & sex \\
3 & Judas Priest & Eat Me Alive & sex \\
4 & Vanity & Strap on Robbie Baby & sex
\end{tabular}




\begin{tabular}{llll}
\hline 5 & Mötley Crüe & Bastard & violence \\
6 & AC/DC & Let Me Put My Love Into You & sex \\
7 & Twisted Sister & We're Not Gonna Take It & violence \\
8 & Madonna & Dress You Up & sex \\
9 & W.A.S.P. & Animal (Fuck Like A Beast) & sex \\
10 & Def Leppard & High 'n Dry & drug and alcohol use \\
11 & Mercyful Fate & Into The Coven & occult \\
12 & Black Sabbath & Trashed & drug and alcohol use \\
13 & Mary Jane Girls & In My House & sex \\
14 & Venom & Possessed & occult \\
15 & Cyndi Lauper & She-Bop & sex, masturbation
\end{tabular}

ii The PMRC are also worried about sexual morality, and often this is entangled with their fears around sexual violence. A discussion of this complicated issue is beyond the remit of this article.

iii With thanks to the reviewer for this observation.

iv It is worth noting that a number of the musicians listed in the Filthy Fifteen are women, including Madonna, but they were not present at the Hearing. We wonder why.

$\checkmark$ Porn is contested feminist territory and recent scholars have worked to understand the ways in which pornography is heterogeneous media form which can sometimes be empowering for women.

vi But it stands in contrast to work by Rafalovich and Schneider (2005) who argue that metal lyrics had become far less misogynistic by the mid-2000s (although more information about their sample would be valued).

vii NB even the discussion of Robin Thicke and Pharrell Williams' 'Blurred Lines' is more interested in the hashtag activism it provoked than in the content of the song (Horeck 2014). 